\title{
The evolution of caste polymorphism in social insects: genetic release followed by diversifying evolution
}

\author{
RAGHAVENDRA GADAGKAR* \\ Centre for Ecological Sciences, Indian Institute of Science, Bangalore 560012, India \\ Animal Behaviour Unit, Jawaharlal Nehru Centre for Advanced Scientific Research, \\ Jakkur P.O., Bangalore 560064, India
}

MS received 30 December 1995; revised 2 April, 1 September, 14 October 1997

\begin{abstract}
Caste polymorphism, defined as the presence within a colony of two or more morphologically differentiated individuals of the same sex, is an important character of highly eusocial insects both in the Hymenoptera (ants, bees and wasps) and in the Isoptera (termites), the only two groups in the animal kingdom where highly eusocial species occur. Frequently, caste polymorphism extends beyond mere variations in size (although the extent of variations in size can be in the extreme) and is accompanied by allometric variations in certain body parts. How such polymorphism has evolved and why, in its extreme form, it is essentially restricted to the social insects are questions of obvious interest but without satisfactory answers at the present time. I present a hypothesis entitled 'genetic release followed by diversifying evolution', that provides potential answers to these questions. I argue that genetic release followed by diversifying evolution is made possible under a number of circumstances. One of them I propose is when some individuals in a species begin to rely on the indirect component of inclusive fitness while others continue to rely largely on the direct component, as workers and queens in social insects are expected to do. Thus when queens begin to rely on workers for most of the foraging, nest building and brood care, and workers begin to rely increasingly on queens to lay eggs - when queen traits and worker traits do not have to be expressed in the same individual-I postulate the relaxation of stabilizing selection and new spurts of directional selection on both queen-trait genes and worker-trait genes (in contrasting directions) leading to caste polymorphism.
\end{abstract}

Keywords. Social evolution; genetic release; diversifying evolution; eusociality; social insects; caste polymorphism.

\section{Social insects}

With very few exceptions, highly eusocial insects, especially ants and termites, are unparalleled in the extent of intraspecies, intrasexual size variations and allometry. The most widespread differentiation is between fertile reproductives (queens) and sterile workers (Wilson 1971). In the ants and termites, subgroups among workers may also be morphologically differentiated among themselves into soldiers or major, minor and media workers, or both (Wilson 1953; Oster and Wilson 1978; Hölldobler and Wilson 1990). Such morphological caste differentiation can be so extreme that different castes, if encountered separately, may get classified as different species (Wheeler 1913). The greatest size variation has been recorded in the Asian marauder ant Pheidologeton diversus (Moffett 1987), where major workers weigh 500 times as much as minor workers and have a head width 10 times as large.

*E-mail: ragh@ces.iisc.ernet.in. 


\section{Evolutionary novelty}

The analogous problem of the appearance of major novel structures and novel lifestyles during evolution has often concerned evolutionary biologists. The solutions suggested appear to vary widely but I shall argue that they have a common underlying theme, namely genetic release followed by diversifying evolution. When an organism becomes adapted to an environmental condition, stabilizing selection will normally prevent it from drifting away from the optimally adapted condition. In such a situation, a new factor can come along and release the organism from the constraints of stabilizing selection and permit new directional selection, thereby permitting diversifying evolution and the appearance of evolutionary novelty. The mechanisms of genetic release and of the subsequent diversification also differ from case to case but the action of stabilizing selection prior to the genetic release and the action of directional selection after the release are recurring features in the appearance of evolutionary novelty. I shall consider four suggested mechanisms for the appearance of evolutionary novelty from the literature and propose a fifth one (for the evolution of caste polymorphism in social insects), all of which involve genetic release followed by diversifying evolution.

\section{Escape and radiation coevolution}

This was first proposed by Ehrlich and Raven(1964) as a hypothesis for the coevolution of families of flowering plants and butterflies and has since been christened 'escape and radiation coevolution' and applied to interactions between parasites and their hosts in general by Thompson (1989, 1994; see also: Gilbert 1990; Berenbaum 1990). When plants produce novel secondary metabolites by mutation and recombination, they become free of their usual insect predators, and thus enter new niches and undergo evolutionary radiation. Mutations and recombination in some of the insect populations permit them to overcome the plant resistance. This allows them to escape from competition with unmodified insect populations, thus permitting entry into new niches and new evolutionary radiation. Here the genetic release from stabilizing selection and the opportunity for new directional selection is on account of ecological factors, namely freedom from the insect herbivores for the plants and freedom from the toxic plant secondary metabolites for the insects.

\section{Enemy-free-space hypothesis for the evolution of host shifts}

Selection of host plants by herbivorous insects is dependent not only on the allelochemical profiles of the host species but on a variety of other host-related factors. The presence or absence of ants on the host plants is an unusual cue that butterflies of the family Lycaenidae use to land as well as to oviposit on particular host plants (Bell 1915-20; Fukuda et al. 1978; Atsatt 1981a, b; Henning 1983; Pierce and Elgar 1985). Because ants provide protection to the butterfly larvae from their predators and parasites this has imortant fitness consequences for the ovipositing female. The use of such 'enemy-free' space for oviposition also has other important consequences for the butterfly species. In many cases this behaviour has led, on the part of the larvae and pupae, to the evolution of the habit of secreting droplets of carbohydrates and amino acids meant for consumption by the ants. Even more important, it has also led to 
significant changes in host range of the butterfly species. The ability to exploit such enemy-free space, especially by specifically rewarding the ants, permits the butterflies to utilize host species not normally available to other species that have not coevolved with ants in this manner. A comparative study of 285 species of lycaenid butterflies led Pierce and Elgar (1985) to conclude that 'lycaenids that are tended by ants feed on a wider range of plants than lycaenids that are not tended by ants' and that $\therefore$ major trends in host plant selection by phytophagous lycaenids may thus be explained in terms of freedoms and constraints that are ultimately the result of pressures exerted by the parasitoids and predators of these butterflies'. Here again the release from stabilizing selection and the opportunity for new directional selection is due to ecological factors, namely freedom from predators and parasites. It should be noted however that escape and radiation coevolution considered in the previous section, unlike the enemy-free-space hypothesis being considered here, was proposed specifically for more large-scale changes involving speciation in plant and butterfly families.

\section{Evolution by gene duplication}

First suggested by Haldane (1932) and Muller (1935), the idea here is that redundant, duplicate copies of genes can accumulate potentially lethal mutations without killing the organism and can eventually give rise to novel genes coding for novel structures via pathways that would be inaccessible to an individual with a single copy of the gene. Thus gene duplication once again releases previously existing constraints due to stabilizing selection and permits new directional selection and hence diversifying evolution. Ohno (1970), the most ardent champion of such a mechanism, has gone to the extent of suggesting that evolution by gene duplication is the only mechanism for the evolution of new genes. Today there is considerable evidence in favour of evolution by gene duplication, which is recognized as an important mechanism for the evolution of genome size and of gene families such as the globin gene superfamily (Hardison 1991; $\mathrm{Li}$ and Graur 1991).

\section{Amelioration of trade-offs between resistance and competitive ability}

Quite often the extent of directional selection on a character is constrained by negative correlation of the character under directional selection with other characters. Perhaps the best-known examples are trade-offs between resistance to insecticides or parasites and general competitive ability. Bacterial and insect strains resistant to antibiotics or insecticides are thought to be kept at very low frequencies in the absence of the antibiotic or insecticide because the resistant phenotype confers no advantage in this environment and indeed may be disadvantageous. An important reason for such negative correlation between the effect of a gene on two or more characters is antagonistic pleiotropy (Caspari 1952; Wright 1968; Dykhuizen and Davies 1980; Falconer 1981; Rose 1982; Service and Lenski 1982; Via 1984; Maynard Smith et al. 1985; Lenski and Levin 1985; Roff 1990; Rose et al. 1990; Scott and Dingle 1990). There are however ways in which such antagonistic pleiotropy can be broken. Two mechanisms for the amelioration of antagonistic pleiotropy have been suggested in the context of trade-offs between insecticide/parasite resistance and general competitive ability. 
One is somewhat trivial and involves selection among alternative alleles conferring resistance and fixation of the one that has the least antagonistic pleiotropic effects (Hall 1983; Cohan and Hoffmann 1986; Lenski 1988a). The other and of more interest in the present context is the selection for epistatic modifiers that ameliorate maladaptive pleiotropic effects (Caspari 1952; Fisher 1958; Uyenoyama 1986). Studies on the development of resistance to the insecticide Diazinon in the sheep blowfly Lucilia cuprina (McKenzie et al. 1982; Clarke and McKenzie 1987) and on the development of resistance to the bacteriophage T4 in the bacterium E. coli (Lenski 1988a, b) provide evidence for both mechanisms. What is most interesting from our point of view of course is that such amelioration of antagonistic pleiotropy and the consequent amelioration of trade-offs result in genetic release from the constraints of stabilizing selection and permit new directional selection and hence diversifying evolution.

\section{Inclusive fitness}

In social insects, especially in the highly eusocial species, one or a small number of colony members (queen/s) monopolize reproduction while the remaining function as sterile workers and spend their entire life working for the welfare of the colony and its queen/s. The evolution of such altruistic sterile worker castes in the social insects was considered paradoxical until Hamilton proposed the theory of inclusive fitness (Hamilton 1964a, b). Today it is common practice to recognize inclusive fitness as having two components, a direct component gained through production of offspring and an indirect component gained through aiding close genetic relatives. Sterile worker castes in social insects are expected to gain fitness exclusively through the indirect component (Hamilton 1964a, b; Wilson 1971, 1975; West-Eberhard 1975; Pamilo and Crozier 1982; Hölldobler and Wilson 1990; Ross and Matthews 1991; Bourke and Franks 1995; Crozier and Pamilo 1996). In no other group is there a comparable level of dependence on the indirect component of inclusive fitness.

I argue that genetic release followed by diversifying evolution, similar to that discussed previously, can occur when some individuals in a species begin to rely on the indirect component of inclusive fitness while others continue to rely on the direct component, as workers and queens in social insects are expected to do. In workers genes concerned with mating and reproduction (which I shall henceforth call queentrait genes) can be thought of as duplicate, redundant copies, and so can genes in queens concerned with foraging, nest building and brood care (which I shall henceforth call worker-trait genes). At first sight this seems erroneous as queens and workers have the same genes. There is convincing evidence, although with a few exceptions, that caste determination is not due to the presence of different genes in different individuals but due to different nutritional, hormonal and other environmental conditions experienced by different individuals (Wilson 1971; Hölldobler and Wilson 1990; Wheeler 1986). There must therefore be different subsets or combinations of genes, even if they are from the same overall set, with different temporal patterns intensities of activity or both that characterize different morphological castes (figure 1). It is hard to imagine how natural selection can perfect the adaptations of different morphological castes for their specific roles without the presence of such caste-specific subsets of genes. Adaptations of castes for their caste-specific functions is indeed most impressive (Wilson 1971; Hölldobler and Wilson 1990; Bourke and Franks 1995). 


\section{Solitary ancestor}

\section{Eusocial species}

genetic

release diversifying

evolution

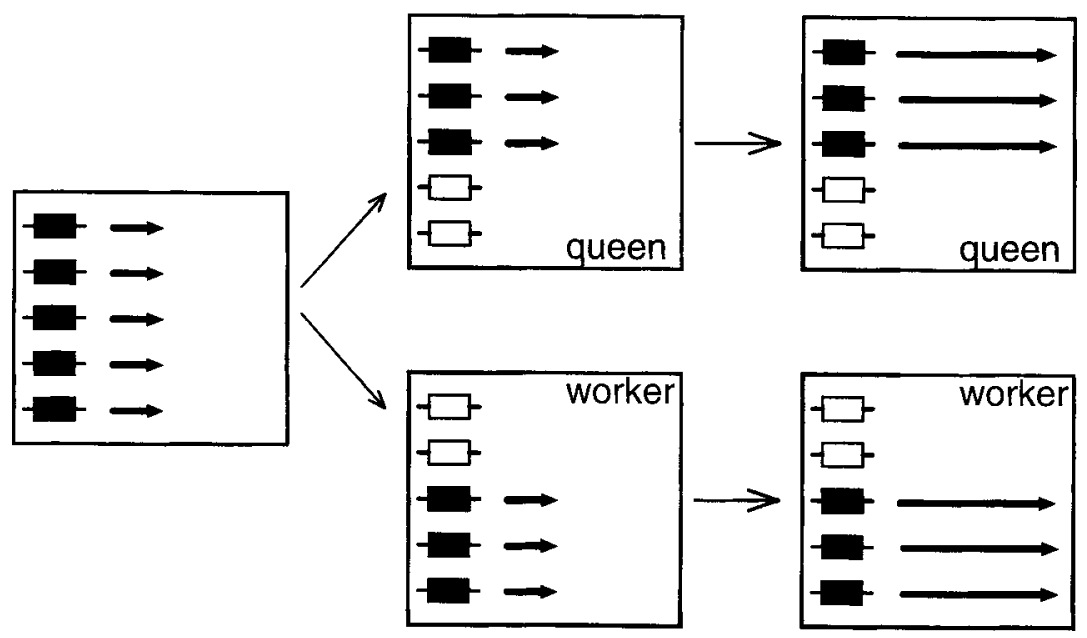

Figure 1. Schematic illustration of the evolution of caste polymorphism in social insects through the process of genetic release followed by diversifying evolution. An example is illustrated with five genes (shaded boxes) in the solitary ancestor with intermediate levels of gene activity (represented by short arrows). In social insects, queens and workers go through different developmental programmes and this could involve activation (shaded boxes) and inactivation (open boxes) of different subsets or combinations of the same overall set of genes present in the solitary ancestor. Notice that gene number three is shown to be active in both queens and workers to illustrate the point that it is the activation of a particular combination of genes that could characterize a caste-specific developmental pathway rather than a necessarily different subset of genes. The inactivation of some genes while the others remain active results in a genetic release for the active genes whose epistatic interactions with the formerly active but presently inactive genes are now broken so that they may undergo new directional selection (represented by the longer arrows emanating from the active genes) leading to diversifying evolution in the final stage.

\section{Genetic release}

In solitary ancestors of eusocial species, directional selection on queen-trait genes as well as worker-trait genes might be expected to have been constrained by the requirement that both queen and worker traits had to be optimized in the same individual, i.e. under a single developmental programme. In other words, antagonistic pleiotropy between queen-trait genes and worker-trait genes would have led, in solitary species, to epistasis for fitness among these genes such that the queen phenotype could not get better beyond a point, without reducing the efficacy of the worker phenotype, and vice versa. However, during the evolution of eusociality, because of the evolution of a control switch that enables queen and worker developmental programmes to be turned on in different individuals, workers begin to rely on queens to mate and provide all or most of the eggs and queens begin to rely on workers to do all or most of the foraging, nest building and brood care. Hence the antagonistic pleiotropy between 
queen-trait genes and worker-trait genes will be broken, leading to a relaxation of stabilizing selection on both sets of genes. This would lead to divergence between workers and queens as the structures previously subjected to stabilizing selection will now begin to stray away from their previously perfected optima.

\section{Diversifying evolution}

Further divergence between queens and workers then becomes possible through a process of diversifying evolution made possible by the genetic release. As a result of genetic release from antagonistic pleiotropy, the epistasis for fitness among queen-trait genes and worker-trait genes will be broken so that both sets of genes can now be subjected to new and more extreme directional selection (in contrasting directions), leading to diversifying evolution and hence to further differentiation of the castes. I postulate that continued feedback between genetic release due to relaxed stabilizing selection and diversifying selection due to new directional selection on the appropriate genes can give rise to the levels of queen-worker dimorphism seen in today's highly social insects (figure 2).

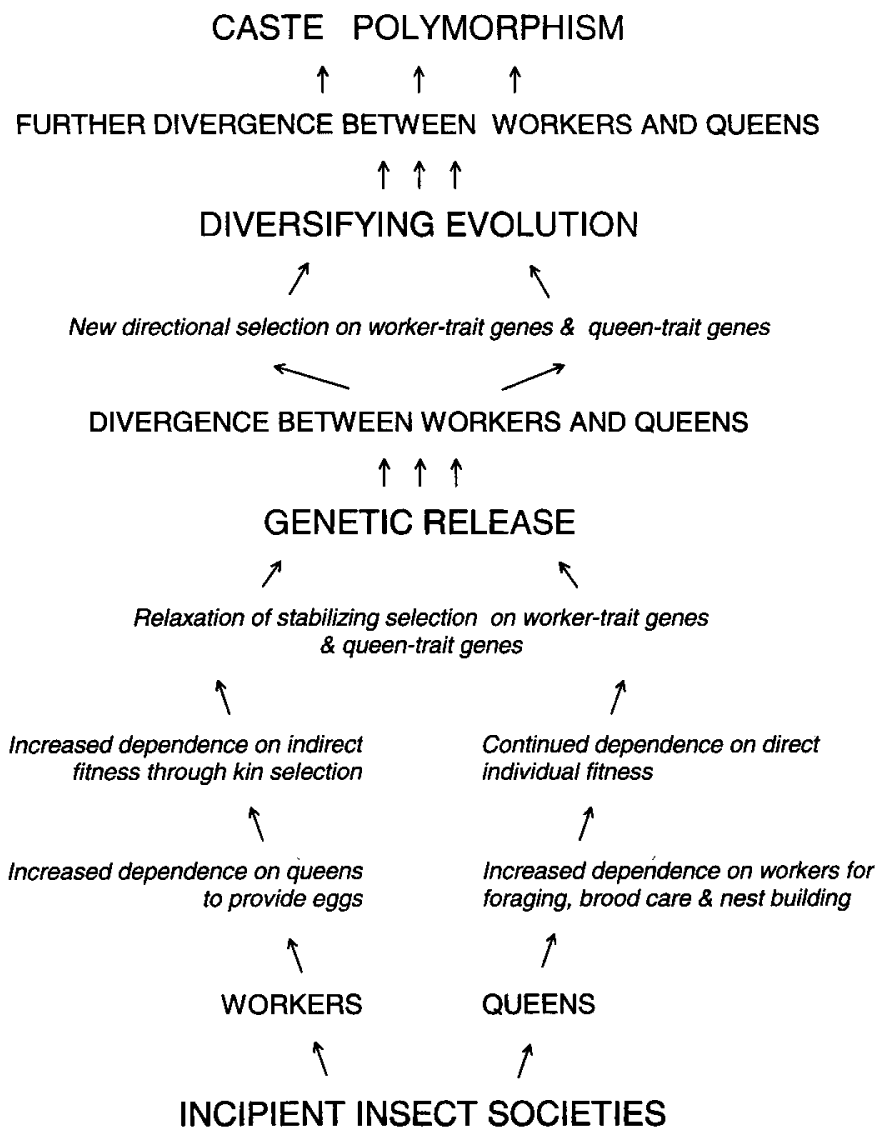

Figure 2. A flow chart for the evolution of caste and subcaste polymorphisms in social insects, based on the idea of genetic release followed by diversifying evolution. 
It is useful to compare and contrast genetic release followed by diversifying evolution as might be expected to happen in social insects with similar phenomena that $I$ have discussed at the beginning of this paper. Unlike in escape and radiation coevolution and enemy-free space, and like in the evolution by gene duplication and amelioration of trade-offs between resistance and competitive ability, in the social insect case, the release is directly due to genetic factors and the constraint causing stabilizing selection is overcome by breaking the epistasis (in the case) between queen-trait and worker-trait genes. But unlike in evolution by gene duplication and amelioration of trade-offs between resistance and competitive ability, the epistasis is broken here when developmental programmes switch on different subsets or combinations of genes (queen-trait and worker-trait genes) in different individuals (queens and workers). Perhaps in contrast to all other four situations, the process of genetic release followed by diversifying evolution in social insects is expected to neither result from nor result in increased genetic variation. If anything there might be a reduction in genetic variation when both queen and worker phenotypes cease to be optimized in the same individual.

\section{Queen-trait and worker-trait genes}

The idea that different subsets or combinations of genes are active in different castes in social insect species is hardly a radical suggestion. This must also be true of males and females in all sexually reproducing organisms because, barring the few genes that reside on sex-specific chromosomes such as the Ychromosome, the genetic constitution is the same in males and females. And yet the two sexes can be phenotypically rather different, which must of course involve activation and inactivation of different subsets or combinations of genes (or a difference in the timing of activation and inactivation) from the same overall set characteristic of the species. Recent molecular-biological investigations of sex determination and dosage compensation in Drosophila melanogaster have uncovered intricate details of the mechanisms of such sex-specific gene expression, which include alternative splicing, transcriptional control, subcellular compartmentalization, and intracellular signal transduction (Burtis 1993; Gorman et al. 1993, 1995; Henikoff and Meneely 1993; Kelley et al. 1995). Although no social insect species has been investigated with any comparable level of sophistication, the idea that different subsets or combinations of genes are active in different castes in social insect species is easily amenable to experimental verification. There is already some evidence of caste-specific gene expression in ants with reference to malate dehydrogenase (Hung and Vinson 1977), $\alpha$-glycerophosphate dehydrogenase (Hung et al. 1977) and adenylate kinase (Craig and Crozier 1978). Indeed, Craig and Crozier (1978) have suggested that 'these pattern differences probably arose via a gene duplication followed by functional divergence leading to one isozyme being superior in workers and the other in queens and males, as determined by the isozymes 'kinetics and the requirements of the castes of the species studied'.

\section{The power of gene duplication in social insects}

During evolution by gene duplication, one copy of the gene remains structurally and functionally intact while the other copy is released from the constraints of stabilizing 
selection and subject to new directional selection (albeit after a period of drift and accumulation of mutations), both copies being present in the same cell. During genetic release followed by diversifying evolution postulated for the social insects, two previously existing sets or combinations of genes are simultaneously released from the constraints of stabilizing selection and subject to new directional selection in opposite direction. Such differential selection is made possible even though the two sets or combinations of genes are in the same individual because they are turned on in different individuals during alternative (queen and worker) developmental pathways. Nevertheless, genetic release followed by diversifying evolution, expected in social insects because some individuals begin to rely on the indirect components of inclusive fitness while others coninue to rely on the direct component, has much in common with evolution by gene duplication. In addition to the similarity, I shall argue below that traditional evolution by gene duplication acquires a new power in a social insect setting where indirect fitness becomes available.

The honey bee queen produces a host of chemical substances that influence the behaviour and physiology of the workers in her colony. Perhaps the most important component of the queen's pheromone blend is 9-keto-(E)2-decenoic acid (9-ODA). Workers too produce mandibular gland secretions that are added to the brood food and may serve as preservatives and nutrients. Instead of the queen's 9-ODA, workers secrete a diacid hydroxylated at the 10th or $\omega$ carbon atom, rather than the 9th or $\omega-1$ carbon atom as in the case of the queen's acids. In other words, queens and workers differ essentially only in the position of the carbon atom that is hydroxylated. But how does this difference arise? As a result of a series of experiments involving analysis of the fate of deuterated test compounds applied to excised queen and worker mandibular glands, using gas chromatography-mass spectrometry (GC-MS), Plettner et al. (1996) have proposed a caste-specific, bifurcated three-step biosynthetic pathway for the production of these compounds.

The starting point is stearic acid, a very common, 18-carbon, straight-chain saturated intermediate of lipid oxidation. In the first step of the proposed pheromone biosynthetic pathway, functionalization is achieved by the addition of a hydroxyl group on either the 18th $(\omega)$ or the 17th $(\omega-1)$ carbon atom in stearic acid. This functionalization which foreshadows the queen-worker differences depending on whether it happens at the $\omega$ or the $\omega$-1 carbon atom is however itself not caste-specific; both $\omega$ and $\omega$-1 functionalizations occur in both castes to about the same extent. In the second step, the 18-carbon hydroxy acids are shortened to give 10-HDA and 9-HDA by the standard chain-shortening cycles of $\beta$-oxidation that normally occur during fatty acid metabolism. It is the $\beta$-oxidation step that is caste-specific - queens preferentially channel the $\omega-1$ compounds and workers the $\omega$ compounds into the $\beta$-oxidation pathway. In the final step, oxidation of the $\omega$ or $\omega$-1 hydroxy group that was added in the first step results in the formation of the diacid in the case of workers and the keto acid in the case of queens.

I have recently hypothesized (Gadagkar 1996a) that the pheromone biosynthetic pathway employed by the workers deviates relatively little from the typical lipid metabolism pathway and is simply adopted from there. The diacid they make can be relatively easily channelled into an energy generating role and its degradation products can be profitably fed into the Krebs cycle. On the other hand, I speculate that the pheromone biosynthetic pathway of the queens is quite a deviation 
from the standard lipid metabolism pathway. In particular, the keto acid is not something one would expect if energy generation is the immediate goal. The expense involved in further breaking down the keto acid makes it a poor candidate to be fed into the Krebs cycle. I therefore speculate that in the course of making their pheromones, the workers are doing more or less what any solitary insect would do anyway for generating energy from lipids, and that their pheromone biosynthetic pathway is therefore the more ancestral one. Conversely, queens have considerably modified the ancestral lipid metabolism pathway to make a pheromone that has only lately (relatively speaking) become necessary. Thus the function of the worker pheromone and the biochemical pathway involved in its production may be thought to be relatively more ancestral and the function of the queen pheromone and the biochemical pathway involved in its production may be thought to be relatively more derived. If this is true, then it is not difficult to see the tremendous advantage of conventional gene duplication in developing the derived condition from the ancestral one. It seems likely that the enzymes involved in the $\beta$-oxidation step give rise to specificity for substrates hydroxylated at the $\omega$ or $\omega-1$ positions. Imagine that the ancestor of the social insect species had a gene that coded for an enzyme which could deal only with the substrate that was hydroxylated at the $\omega$ position. The workers in the descendent social species can continue to use this gene and this enzyme to make worker pheromones which may perhaps have even been made by the ancestor. A duplication of the gene involved can permit the evolution of an alternative enzyme which can handle the substrate hydroxylated at the $\omega-1$ position. We know that such a substrate must already have been available because both kinds of hydroxylations occur to an equal extent in both queens and workers. The duplicated gene would now be free to evolve in new directions without reduced fitness due to the reduction in the efficiency of energy production through lipid metabolism. The new directional evolution can sometimes give rise to substrates with remarkable properties such as the queen pheromone. A similar chance occurrence of such a mutation could hardly have been utilized effectively by a solitary species. Because social insects set aside some individuals for the sole purpose of monopolizing reproduction and inhibiting and controlling all others, they are in a special position to exploit such a consequence of conventional gene duplication and evolve in directions that are not open to solitary species.

\section{From solitary to the highly eusocial}

Demographic factors such as initial variations in time taken to attain reproductive maturity, for example, will make it worthwhile for some individuals to adopt workerlike roles and for others to assume queen-like roles, leading to the origin of eusociality (West-Eberhard 1978; Craig 1983; Gadagkar 1991, 1996b). I have suggested that such demographic factors will coevolve with eusociality and become more pronounced because late reproducers will, for example, have a smaller selective disadvantage in a eusocial species compared to a solitary species because of the possibility of gaining indirect fitness in the former (Gadagkar 1991, 1996b). I now suggest genetic release followed by diversifying evolution as a mechanism for such coevolution that can potentially lead to sufficient divergence between queens and workers to give rise to caste polymorphism. 
What this means is that we can envisage the evolution of highly eusocial species starting from completely solitary ancestors through selection for developmental plasticity. In solitary species, any character such as time taken to attain reproductive maturity, ovary size, mandible size, etc. would have limited developmental plasticity on account of stabilizing selection, because, as explained above, both queen and worker functions would have to be optimized under a single developmental programme. But even here, under the right ecological, genetic or demographic conditions (Gadagkar 1991, 1996b), individuals at the extremes of the distribution of values for these characters would be selected to take up predominantly or exclusively queen-like or worker-like roles. For example, individuals that have to wait only a short time before attaining reproductive maturity or have larger than average ovaries would be fitter as queens compared to individuals as the opposite ends of the distributions. Conversely, individuals with delayed attainment of reproductive maturity, smaller than average ovaries or larger than average mandibles (useful say, in transporting food back to the nest) would be fitter as workers than individuals at the opposite ends of the distributions. This stage may thus be thought of as the origin of eusociality. Perhaps it should be emphasized that genetic release followed by diversifying evolution is not being postulated as being involved in the origin of eusociality but only for the subsequent morphological, physiological and behavioural differentiation of queens and workers. Thus, as the worker-like individuals begin to rely increasingly on the indirect component of inclusive fitness and queen-like individuals continue to depend on the direct component, there would be relaxed stabilizing selection and increased directional selection on appropriate genes as described above. As West-Eberhard (1979) has argued, such a process can go far enough to make intermediate individuals to be good neither at being queens nor at being workers and thus reinforce the process of morphological caste differentiation. Indeed, I suggest that genetic release followed by diversifying evolution as discussed and interpreted here provides a mechanism for West-Eberhard's $(1979,1987,1989,1992)$ model of the evolution of insect sociality through 'alternative phenotypes'.

I believe that genetic release followed by diversifying evolution, made possible when some individuals begin to rely on the indirect component of inclusive fitness while others continue to rely on the direct component, is a more general evolutionary principle, of which the evolution of caste and subcaste polymorphisms in social insects constitutes one obvious application. Another application, in a somewhat different context, is that cell differentiation during development of multicellular organisms may be thought of as being facilitated by a similar process of genetic release followed by diversifying evolution except that now, the subsets or combinations of genes subject to relaxed stabilizing selection and increased directional selection, would be found in different cells of the same individual rather than either in the same cell (as in the case of evolution by gene duplication) or in different individuals (as in the evolution of caste polymorphism in social insects suggested above). This comparison between the possible roles of genetic release followed by diversifying evolution, in caste differentiation in social insects on the one hand, and cell differentiation on the other, underpins the heuristic value of considering highly social insects as superorganisms and comparing queens with the germ line and workers with the soma, a view that we owe to William Morton Wheeler (1911) but has recently been revived (Wilson and Sober 1989; Moritz and Southwick 1992) from near oblivion (Wilson 1967). 


\section{Acknowledgements}

My research is supported by grants from the Department of Science and Technology and the Ministry of Environment and Forests of the Government of India and the Homi Bhabha and B. P. Pal National Environment Fellowships. I began thinking about the ideas presented here while I was visiting the University of Wurzburg. I thank Bert Hölldobler for the invitation and financial support through the Leibniz award of the German Research Council (DFG). I also thank Bert Hölldobler, Wolfgang Kirchner, Jürgen Heinz, Madhav Cadgil and V. Nanjundiah, Mary Jane WestEberhard, John Bonner, Ross Crozier and Diana Wheeler for many helpful comments on a previous version of this paper. I especially thank Amitabh Joshi for suggesting the subtitle, for encouraging me to view the problem of caste polymorphism in social insects in a broad context and, along with Vani Brahmachari, for bringing much literature to my attention.

\section{References}

Atsatt P. R. 1981a Ant-dependent food plant selection by the mistletoe butterfly Ogyris amaryllis (Lycaenidae). Oecologia 48: 60-63

Atsatt P. R. 1981b Lycaenid butterflies and ants: Selection for enemy-free space Am. Nat. 18: 638-654

Bell T. R. 1915-1920 The common butterflies of the plains of India. J. Bombay Nat. Hist. Soc. vols. 23-27

Berenbaum M. R. 1990 Coevolution between herbivorous insects and plants: Tempo and orchestration. In Insect life cycles-genetics, evolution and coordination (ed.) F. Gilbert (London: Springer) pp. 87-99

Bourke A. F. G. and Franks N. R. 1995 Social evolution in ants (Princeton: Princeton University Press)

Burtis K. C. 1993 The regulation of sex determination and sexually dimorphic differentiation in Drosophila. Curr. Opin. Cell Biol. 5: 1006-1014

Caspari E. 1952 Pleiotropic gene action. Evolution 6: 1-18

Clarke G. M. and Mckenzie J. A. 1987 Developmental stability of insecticide resistant phenotypes in glow fly: A result of canalizing natural selection. Nature 325: 345-346

Cohan F. M. and Hoffmann A. A. 1986 Genetic divergence under uniform selection. II. Different responses to selection for knockdown resistance to ethanol among Drosophila melanogaster populations and their replicate lines. Genetics 114: 145-163

Craig R. 1983 Subfertility and the evolution of eusociality by kin selection. J. Theor. Biol. 100: 379-397

Craig R. and Crozier R. H. 1978 Caste-specific locus expression in ants. Isozyme Bull. 11: 64-65

Crozier R. H. and Pamilo P. 1996 Evolution of social insect colonies. Sex allocation and kin-selection (eds.) R. M. May and P. Harvey (Oxford: Oxford University Press)

Dykhuizen D. and Davies M. 1980 An experimental model: Bacterial specialists and generalists competing in chemostats. Ecology 61: 1213-1227

Ehrlich P. R. and Raven P. H. 1964 Butterflies and plants: a study in coevolution. Evolution 18: 568-608

Falconer D. S. 1981 Introduction to quantitative genetics 2nd edn (London and New York: Longman)

Fisher R. A. 1958 The genetical theory of natural selection (New York: Dover)

Fukuda H., Kubo K., Takeshi K., Takahashi A., Takahashi M., Tanaka B., Wakabayashi M. and Shirozu T. 1978 Insects'life in Japan. III. Butterfies (Tokyo: Hoikushu)

Gadagkar R. 1991 Demographic predisposition to the evolution of eusociality-A hierarchy of models. Proc. Natl. Acad. Sci. USA 88: 10993-10997

Gadagkar R. 1996a What's the essence of royalty-one keto group? Curr. Sci. 71: 975-980

Gadagkar R. 1996b The evolution of eusociality, including a review of the social status of Ropalidia marginata. In Natural history and evolution of paper wasps (eds.) S. Turillazzi and M. J. West-Eberhard (Oxford: Oxford University Press) pp. 248-271

Gilbert F. 1990 Size, phylogeny, and life-history in the evolution of feeding specialization in insect predators. In Insect life cycles-genetics, evolution and co-ordination(ed.) F. Gilbert (London: Springer) pp. 101-124

Gorman M., Kuroda M. I. and Baker B. S. 1993 Regulation of the sex-specific binding of the maleless dosage compensation protein to the male X chromosome in Drosophila. Cell 72: 39-49 
Gorman M., Franke A. and Baker B. S. 1995 Molecular characterization of the male-specific lethal-3 gene and investigations of the regulation of dosage compensation in Drosophila. Development 121: $463-475$

Haldane J. B. S. 1932 The causes of evolution (London: Longmans Green)

Hall B. G. 1983 Evolution of new metabolic functions in laboratory organisms. In Evolution of genes and proteins (eds.) M. Nei and R. K. Koehn (Sunderland, Mass., USA: Sinauer) pp. 234-257

Hamilton W. D. 1964a The genetical evolution of social behaviour I. J. Theor. Biol. 7: 1-16

Hamilton W. D. 1964b The genetical evolution of social behaviour II. J. Theor. Biol. 7: 17-52

Hardison R. C. 1991 Evolution of globin gene families. In Evolution at the molecular level (eds.) R. K. Selander, A. G. Clark and T. S. Whittam (Sunderland, Mass., USA: Sinauer) pp. 272-289

Henikoff S. and Meneely P. M. 1993 Unwinding dosage compensation. Cell. 72: 1-2

Henning S. F. 1983 Biological groups within the Lycaenidae (Lepidoptera). J. Entomol. Soc. S. Afr. 46: 65-85

Hölldobler B. and Wilson E. O. 1990 The ants (Cambridge, USA: Harvard University Press: Cambridge)

Hung A. C. F. and Vinson S. B. 1977 Interspecific hybridization and caste specificity of proteins in fire ant. Science 196: 1458-1460

Hung A. C. F. Dowler M. and Vinson S. B. 1977 Alpha-glycerophosphate dehydrogenase isozyme of the fire ant Solenopsis invicta. Isozyme Bull. 10: 29

Kelley R. L., Solovyeva I., Lyman L. M., Richman R., Solovyev V. and Kuroda M. I. 1995 Expression of Ms1-2 causes assembly of dosage compensation regulators on the $\mathrm{X}$ chromosomes and female lethality in Drosophila. Cell. 81: 867-877

Lenski R. E. 1988a Experimental studies of pleiotropy and epistasis in Escherichia coli. I. Variation in competitive fitness among mutants resistant to virus T4. Evolution $42: 425-432$

Lenski R. E. 1988b Experimental studies of pleiotropy and epistasis in Escherichia coli. II. Compensation for maladaptive effects associated with resistance to virus T4. Evolution 42: 433-440

Lenski R. E. and Levin B. R. 1985 Constraints on the coevolution of bacteria and virulent phage: A model, some experiments, and predictions for natural communities. Am. Nat. 125: 585-602

Li W.-H. and Graur D. 1991 Fundamentals of molecular evolution (Sunderland, Mass., USA: Sinauer)

McKenzie J. A., Whitten M. J. and Adena M. A. 1982 The effect of genetic background on the fitness of diazinon resistance genotypes of the Australian sheep blowfly, Lucilia cuprina. Heredity 49: 1-9

Maynard Smith J., Burian R., Kauffman S., Alberch P., Campbell J., Goodwin B., Lande R., Raup D. and Wolpert L. 1985 Developmental constraints and evolution. Q. Rev. Biol. 60: 265-287

Moffett M. 1987 Division of labor and diet in the extremely polymorphic ant Pheidologeton diversus. Nat. Geogr. Res. 3: 282-304

Moritz R. F. A. and Southwick E. E. 1992 Bees as superorganisms-An evolutionary reality (Berlin: Springer)

Muller H. J. 1935 The origination of chromatin deficiencies as minute deletions subject to insertion elsewhere. Genetics 17: 237-252

Ohno S. 1970 Evolution by gene duplication (Berlin: Springer)

Oster G. F. and Wilson E. O. 1978 Caste and ecology in the social insects (Princeton: Princeton University Press)

Pamilo P. and Crozier R. H. 1982 Measuring relatedness in natural populations: Methodology. Theor. Popul. Biol. 21: 171-193

Pierce N. E. and Elgar M. A. 1985 The influence of ants on host plant selection by Jalmenus evagoras, a myrmecophilous lycaenid butterfly. Behav. Ecol. Sociobiol. 16: 209-222

Plettner E. Slessor K. N., Winston M. L. and Oliver J. E. 1996 Caste-selective pheromone biosynthesis in honeybees. Science 271: 1851-1853

Roff D. A. 1990 Understanding the evolution of insect life-cycles: The role of genetic analysis. In Insect life cycles-genetics, evolution and co-ordination (ed.) F. Gilbert (London: Springer) pp. 5-27

Rose M. R. 1982 Antagonistic pleiotropy, dominance, and genetic variation. Heredity 48: 63-78

Rose M. R., Graves J. L. and Edward W. 1990 The use of selection to probe patterns of pleiotropy in fitness characters. In Insect life cycles-genetics, evolution and co-ordination (ed.) F. Gilbert (London: Springer) pp. $29-42$

Ross K. G. and Matthews R. W. (eds.) 1991 The social biology of wasps (Ithaca and London: Cornell University Press)

Scott S. M. and Dingle H. 1990 Developmental programmes and adaptive syndromes in insect life-cycles. In Insect. life cycle-genetcs, evolution and co-ordination (ed.) F. Gilbert (London: Springer) pp. 69-85

Service P. M. and Lenski R. E. 1982 Aphid genotypes, plant phenotypes, and genetic diversity: A demographic analysis of experimental data. Evolution 36: 1276-1282 
Thompson J. N. 1989 Concepts of coevolution. Trends Ecol. Evol. 4: 179-183

Thompson J. N. 1994 The coevolutionary process (Chicago and London: The Univeristy of Chicago Press) Uyenoyama M. K. 1986 Pleiotropy and the evolution of genetic systems conferring resistance to pesticides. In Pesticide resistance: strategies and tactics for management (eds.) National Research Council Committee on Strategies for the Managament of Pesticide Resistant Pest Populations (Washington DC: National Academic Press) pp. 207-221

Via S. 1984 The quantitative genetics of polyphagy in an insect herbivore. II. Genetic correlations in larval performance within and across host plants. Evolution 38: 896-905

West-Eberhard, M. J. 1975 The evolution of social behavior by kin selection. Q. Rev. Biol. 50: 1-33

West-Eberhard M. J. 1978 Polygyny and the evolution of social behavior in wasps. J. Kansas Entomol. Soc. 51: $832-856$

West-Eberhard M. J. 1979 Sexual selection, social competition, and evolution. Proc. Am. Philos. Soc. 123: 222-234

West-Eberhard M. J. 1987 Flexible strategy and social evolution. In Animal societies: theories and facts (eds.) Y. Itô, J. L. Brown and J. Kikkawa (Tokyo: Japan Scientific Societies Press) pp. 35-51

West-Eberhard M. J. 1989 Phenotypic plasticity and the origins of diversity. Annu. Rev. Ecol. Syst. 20: 249-278

West-Eberhard M. J. 1992 Behavior and evolution. In Molds, molecules, and metazoa, growing points in evolutionary viology (eds.) P. R. Grant and H. S. Horn (Princeton: Princeton University Press) pp. 57-75

Wheeler D. E. 1986 Developmental and physiological determinants of caste in social Hymenoptera: evolutionary implications. Am. Nat. 128: 13-34

Wheeler W. M. 1991 The ant-colony as an organism. J. Morph. 22: 307-325

Wheeler W. M. 1913 The ants-their structure, development and behaviour (New York Columbia University Press)

Wilson E. O. 1953 The origin and evolution of polymorphism in ants. Q. Rev. Biol. 28: 136-156

Wilson E. O. 1967 The superorganism concept and beyond. In L'effet de group chez les animaux (Paris: CNRS) pp. 1-13

Wilson E. O. 1971 The insect societies (Cambridge, USA: Harvard Univeristy Press)

Wilson E. O. 1975 Sociobiology: The new synthesis (Cambridge, USA: Harvard University Press)

Wilson D. S. and Sober E. 1989 Reviving the superorganism. J. Theory. biol 136: 337-356

Wright S. 1968 Evolution and genetics of populations. Vol 1 Genetics and biometric foundations (Chicago: University of Chicago Press) 